\title{
Índices financieros, la clave de la finanza administrativa aplicada a una empresa manufacturera
}

\section{Financial indicators, the key to administrative finance applied to a manufacturing company}

\author{
Kenia Lizzeth Carchi Arias \\ https://orcid.org/0000-0003-4023-4015 \\ Marjorie Katherine Crespo García \\ https://orcid.org/0000-0002-4260-1811 \\ Universidad Metropolitana del Ecuador, Ecuador
}

Susana Emperatriz González Malla

https://orcid.org/0000-0003-4445-9422

Instituto Tecnológico Superior Dr. José Ochoa León, Ecuador

Eddy Javier Romero Romero

https://orcid.org/0000-0002-1498-0615

Instituto Tecnológico Superior El Oro, Ecuador

Autor por correspondencia: k.c.e.c2109@hotmail.com; mcrespo@umet.edu.ec; susanitagoma@gmail.com; eromero.itso@gmail.com

Fecha de recepción: 10 de septiembre de 2019 - Fecha de aceptación: 05 de febrero de 2020

\section{Resumen}

Este trabajo tiene como objetivo presentar el análisis financiero de la empresa ecuatoriana Colineal Corporation Cía. Ltda., a través de la aplicación de indicadores financieros de liquidez, rentabilidad, endeudamiento y generación de valor, que permita mejorar la toma de decisiones en la gestión de operación, inversión y financiamiento. Así mismo, para cumplir con lo propuesto se empleó una metodología cuantitativo transversal, argumentada con teorías de autores sobre los temas financieros, la investigación es tipo explicativa-longitudinal debido al análisis comparativo de los estados financieros que se obtiene de la superintendencia de compañía de valores y seguros, contrastando con el comportamiento del entorno macroeconómico cambiante a los que se expone el sector manufacturero del Ecuador, incidiendo en el rendimiento financiero de las empresas. Como resultado del comportamiento financiero es evaluar la generación de valor que permita la creación de ventajas competitivas para una administración financiera eficiente, que impacta en el crecimiento futuro de la empresa.

Palabras claves: finanzas administrativas; indicadores financieros; sector manufacturero; decisiones empresariales

\section{Abstract}

This work aims to present the financial analysis of the company Colineal Corporation Cia. Ltda. through the application of financial indicators of liquidity, profitability, indebtedness and value generation, which allows to improve decision-making in the management of operation, 
investment and financing. Likewise, in order to comply with the proposal, a methodology with a mixed approach was used, argued with theories of authors on financial issues, the research is explanatory-longitudinal type due to the comparative analysis of the financial statements obtained from the superintendence of the company's securities and insurance, contrasting with the behavior of the changing macroeconomic environment to which Ecuador's manufacturing sector is exposed, affecting the financial performance of companies. As a result of the financial behavior is to evaluate the generation of value that allows the creation of competitive advantages for an efficient financial administration, which impacts the future growth of the company.

Key words: administrative finance; financial indicators; manufacturing sector; business decisions

\section{Introducción}

La competitividad en la actualidad es uno de los factores más manifiestos en la sostenibilidad empresarial; esto se debe a los grandes cambios del entorno al que se enfrentan los diferentes sectores económicos, poniendo en riesgo el desarrollo y crecimiento de muchas empresas. Partiendo de este contexto, los negocios se han vuelto vulnerables a desequilibrios financieros, que exige la adaptación de nuevas estrategias de gestión de recursos que garantice una mejor estructura empresarial (Puga M. , 2015). Así mismo, Cardona Olaya, Martínez, Velásquez , \& López (2014) expone que la alta gerencia debe asumir con responsabilidad empresarial las decisiones que toman; es por ello, que tienen la necesidad de responder financieramente a la realidad económica del negocio.

Por ello, radica la importancia de este estudio, en emplear las finanzas administrativas como un arte en la administración de recursos económicos de una empresa, puesto que, la gestión del dinero es de vital interés para la liquidez de la organización, dependiendo esencialmente de la actividad del giro del negocio, del mismo modo al proceso organizacional y operativo que tiene la empresa tal cual, además, se comporta en dependencia de los factores internos y externos que influyen en el mercado (Cheol \& Bruce G., 2007).

Según la Teoría de Baena, (2014) Las finanzas administrativas son una función que asume el administrador financiero de la institución sea de servicios, de producción, de comercialización o manufacturera, priorizando a los asuntos financieros. Acotando a ésta teoría se puede decir que el análisis financiero es un estudio de aquel proceso recopilado de un suceso pasado de un periodo de tiempo determinado, cuyo objetivo es la comparación de los datos cuantitativos y cualitativos, para lograr obtener un diagnóstico de la situación actual de la empresa; además de demostrar todos los cambios que la empresa ha experimentado dentro del ciclo económico; coadyuvando a los gerentes o dueños de las empresas manufactureras a una adecuada toma de decisiones" (Crespo, 2018). Al referirse en este caso, el sector industrial manufacturero en los últimos cinco años juega un rol fundamental dentro de la economía a nivel mundial, debido no solo al trabajo que tiene en transformar la materia prima, sino, en la gestión de procesos eficientes y eficaces que aplican en cada una de sus áreas, teniendo como resultado mayores niveles de productividad y competitividad, permitiendo que la participación en el mercado en el año 2017 crezca a un ritmo de $3.1 \%$ respecto al año 2016, demostrando la importancia de este sector en la economía ecuatoriana.

Así mismo, de acuerdo al INEC, a septiembre de 2017 esta actividad generó el 11\% del empleo total del país. (EKOS, 2018). Por otra parte, el Plan Nacional de Inversiones del Comexi y de la Corpei, el sector forestal ha sido considerado como sector prioritario para las 
inversiones y uno de los que ofrece mayor potencial de crecimiento y desarrollo en el país. Si se consideran todos los bienes y servicios ambientales, el aporte del bosque supera los $\$ 600$ millones/año, por lo que, su contribución en el 2018 al PIB es aproximadamente del 3,2 \%, incidiendo a que la industria maderera ocupe el $6 \%$ de participación en el mercado y el $15 \%$ en el crecimiento económico del país.

Debido a la participación dinámica que tiene este sector Walter Rostow (Nobel de Economía en 1987) es su teoría expresa que al existir un incremento de la tasa de crecimiento de la manufactura genera un aumento de la productividad en el mismo sector económico; por otra parte, estudiar el análisis del entorno interno tiene que ver con la dimensión estratégica de lo que es la gerencia, área responsable de la decisiones estratégicas que toma la organización los equipos de trabajo que participan para involucrarlos en ellos. Una decisión estratégica no solo se toma en base al conocimiento sino en la capacidad y experiencia productiva, tecnología, sus costos, su talento humano; sino sobre la comprensión de la dinámica del entorno que rodea a la organización. Es decir, no es lo mismo una empresa que se mueve en el mercado monopolizado que un mercado que se mueve en una amplia competencia o un mercado local o de carácter internacional; por ende, la comprensión del entorno depende de la fundamentación macro y micro económico que considera al estudio del entorno bastante compleja. En términos económicos, sociales, jurídicos, políticos, tecnológicos, ambientales tanto a nivel local, nacional o en el mundo no se pueden sustraer de ciertos conflictos que se desarrollan en el mundo en función de las diferentes variables que están inmersas y que la velocidad con que cambian las cosas, cada vez es en el menor tiempo. (Acuña, 2016).

En base a lo mencionado anteriormente, este trabajo investigativo tienen como principal objetivo realizar el análisis financiero aplicado a la empresa manufacturera ecuatoriana denominada Colineal Cía. Ltda.; a partir de la aplicación de indicadores que faciliten la toma de decisiones gerenciales; para ello es primordial realizar la fundamentación teórica de los índices financieros que se aplican, y su importancia en las decisiones de la organización; así mismo, se hace una valoración actual de las inversiones del sector manufacturero y su participación en el crecimiento económico. Posteriormente, se presenta la metodología utilizada para presentar los resultados; el cual consiste en la valoración económica- financiera de la empresa de estudio y finalmente se da las conclusiones.

\section{Fundamentación teórica de los indicadores financieros, como herramienta clave en las finanzas administrativas}

Entre los indicadores que describe este trabajo es el índice de liquidez, que surge de la necesidad de medir la capacidad que tienen las empresas para cancelar sus obligaciones de corto plazo. Sirven para establecer la facilidad o dificultad que presenta una compañía para pagar sus pasivos corrientes al convertir a efectivo sus activos corrientes (Angulo, 2012).

Conforme a lo expuesto anteriormente, este análisis permite determinar qué pasaría si a la empresa se le exigiera el pago inmediato de todas sus obligaciones en el lapso menor a un año, recurriendo a evaluar a la empresa desde el punto de vista del pago inmediato de sus acreencias corrientes en caso excepcional. 
Tabla 1

Indicadores de Liquidez

\begin{tabular}{|c|c|c|c|}
\hline \multirow{3}{*}{\multicolumn{2}{|c|}{$\begin{array}{c}\text { Indicador } \\
\text { corriente }^{\text {Razón }} \\
\end{array}$}} & Fórmula & Evalúa \\
\hline & & Activo corriente & \multirow{2}{*}{$\begin{array}{l}\text { Evalúa la capacidad de responder a las } \\
\text { obligaciones exigibles de corto plazo }\end{array}$} \\
\hline & & $\overline{\text { Pasivo corriente }}$ & \\
\hline & \multirow[t]{2}{*}{ Prueba ácida } & Activo corriente - Inventarios & \multirow{2}{*}{$\begin{array}{l}\text { Evalúa la capacidad de cubrir deudas a corto } \\
\text { plazo, sin depender de altos niveles de rotación } \\
\text { de inventario. }\end{array}$} \\
\hline & & $\begin{array}{c}\text { Pasivo corriente } \\
\end{array}$ & \\
\hline Trabajo & Capital de & $\begin{array}{l}\text { Activo corriente - Pasivo } \\
\text { corriente }\end{array}$ & $\begin{array}{l}\text { Evalúa lo que tiene la empresa, una vez } \\
\text { deducido sus obligaciones a corto plazo. }\end{array}$ \\
\hline
\end{tabular}

Elaboración propia, tomado del libro de (Baena, 2014)

\section{Análisis de eficiencia en la productividad}

Boudreaux (2016) considera importante analizar la eficiencia a partir de indicadores de actividad, puesto que permite determinar el grado de rotación de inventarios y conocer alcances empresariales para lograr la recuperación de los créditos y el pago de las obligaciones. Los ratios financieros de actividad que se consideran para este análisis se muestran a continuación:

Tabla 2

Indicadores de Eficiencia

\begin{tabular}{|c|c|c|}
\hline $\begin{array}{l}\text { Indicadores } \\
\text { Financieros }\end{array}$ & Fórmula & Evalúa \\
\hline \multirow{3}{*}{ Rotación de Inventario } & $\begin{array}{c}\text { Veces } \\
\text { Costo de Ventas }\end{array}$ & \multirow{3}{*}{$\begin{array}{l}\text { La eficiencia en la gestión de salida de inventario. } \\
\text { Una rotación baja significa que hay inventario sin } \\
\text { movimientos; caso contrario, una rotación alta } \\
\text { significa que el mismo sale rápidamente. }\end{array}$} \\
\hline & $\begin{array}{l}\overline{\text { Promedio de invetario }} \\
\text { Días } \\
360 \text { días }\end{array}$ & \\
\hline & $\overline{\text { Rotación de inventario }}$ & \\
\hline \multirow{5}{*}{$\begin{array}{l}\text { Rotación de cuentas por } \\
\text { cobrar }(\mathrm{CxC})\end{array}$} & Ventas Netas & \multirow{5}{*}{$\begin{array}{l}\text { La cantidad de veces que tiene una empresa por } \\
\text { cobrar a los clientes, para asegurar la salud financiera } \\
\text { del negocio. } \\
\text { Una Rotación de CxC alta significa que la empresa } \\
\text { opera más al contado, caso contrario la empresa tiene } \\
\text { políticas flexibles de crédito. }\end{array}$} \\
\hline & & \\
\hline & Días & \\
\hline & 360 días & \\
\hline & Rotación de CxC & \\
\hline \multirow{6}{*}{$\begin{array}{l}\text { Rotación } \\
\text { proveedores }\end{array}$} & Veces & \multirow{6}{*}{$\begin{array}{l}\text { El cumplimiento de pago a proveedores, con el uso de } \\
\text { recursos líquidos de la empresa. Si el número de veces } \\
\text { es alto, significa mayor eficiencia en el pago a } \\
\text { proveedores. Es importante que la determinación de } \\
\text { este indicador se ajuste al comportamiento } \\
\text { inflacionario. }\end{array}$} \\
\hline & $\begin{array}{l}\text { Compras de } \\
\text { inventario }\end{array}$ & \\
\hline & Proveedores & \\
\hline & promedio & \\
\hline & $\begin{array}{l}\text { Dias } \\
360 \text { días }\end{array}$ & \\
\hline & Rotación de Proveedores & \\
\hline
\end{tabular}

Elaboración propia, tomado del libro de (Baena, 2014)

\section{Análisis de diagnóstico financiero}

Es imprescindible diagnosticar una empresa a partir del comportamiento económico de la misma (Acuña, 2016). Como lo menciona Ross, Randolf, \& Jordán, (2010) el análisis financiero implica indagar en términos más dinámicos los ingresos generados por las ventas, 
el flujo de efectivo y la capacidad de responder a las obligaciones propias del negocio; valorando fuentes externas de valoración de mercado. A continuación, se recomiendan los siguientes indicadores:

\section{Capital de Trabajo Operativo (KTO)}

El KTO muestra la limitación de dinero, con que cuenta una empresa para cubrir costos y gastos de corto plazo dentro del desarrollo normal de su negocio, el mismo que, se ve representado en los inventarios que acumula la empresa y las cuentas pendientes de cobro de cartera; así mismo, (Finanzas Dual, 2008) expone que en este análisis no se toma en cuenta al efectivo generado por las ventas ni las inversiones. Para obtener el resultado se considera la siguiente fórmula: Disponible + cuentas por cobrar + inventarios.

\section{Capital de trabajo neto operativo (KTNO)}

Boudreaux, (2016) manifiesta que el capital de trabajo neto operativo comprende un concepto mucho más profundo que el concepto contable de capital de trabajo, y en este se considera única y exclusivamente los activos que directamente intervienen en la generación de recursos, menos las cuentas por pagar. Sin embargo, Angulo (2012) enfatiza que la determinación de este indicador excluye las partidas de efectivo e inversiones a corto plazo. Es decir, en primer lugar, se supone que el efectivo en una empresa debe ser lo menos posible, debe aproximarse a cero, ya que el efectivo no genera rentabilidad. Tener grandes sumas disponibles es un error financiero. La fórmula ideal para el cálculo del capital de trabajo neto operativo, es: Inventarios + cuentas por cobrar - las cuentas por pagar a proveedores.

\section{Indicador financiero EBITDA}

Es un indicador financiero que mide la capacidad pura de la empresa para generar utilidades, antes de ser contaminada por disposiciones contables, financieras y tributarias. Permite comparar el desempeño de una empresa y compararlo con el desempeño de otra, así la actividad económica sea diferente, facilitándole al gerente financiero la toma de decisiones de inversión (Eslava, 2010).

Por otra parte, León, (2010) expone un análisis con enfoque proyectual, que si se obtiene el EBIDTA positivo indicará la rentabilidad, incluyendo gastos financieros y fiscales; pero, la rentabilidad final del mismo dependerá de la gestión respecto a las políticas contables de la empresa. Por lo contrario, si el EBIDTA es negativo, se descarta la viabilidad del proyecto o decisión de inversión. Para determinarlo se debe aplicar la suma de la Utilidad Operativa + Depreciaciones + Amortizaciones.

\section{Valor Económico Añadido (EVA)}

El EVA es la rentabilidad obtenida por la empresa deduciendo la utilidad de operación neta de impuestos, el costo de capital de los recursos propios y externos que utiliza. Si el resultado es positivo, la empresa habrá generado una rentabilidad por encima de su costo de capital, lo que le genera una situación de creación de valor. Pero, si es negativo indica que los rendimientos son menores a lo que cuesta generarlos y por lo tanto destruye valor para los accionistas (Acuña, 2016). 
Es decir, el EVA sirve para evaluar la generación de valor de la empresa y constituye una herramienta gerencial clave para el planeamiento estratégico, la toma de decisiones y la evaluación del desempeño por áreas de responsabilidad.

Tabla 3

Fórmula de cálculo EVA

\begin{tabular}{ll}
\hline Indicador. & Ecuación. \\
\hline EVA & $\mathrm{RN}-(\mathrm{CPPC} * \mathrm{C})$ \\
\hline & Elaboración propia, tomado de libro de (Martínez, 2005)
\end{tabular}

$\mathbf{R N}=$ Resultado neto después de impuestos

CPPC $=$ Costo promedio ponderado de Capital

$\mathbf{C}=$ Capital invertido por la Empresa

\section{Importancia del análisis de rentabilidad}

Desde un enfoque empresarial, el análisis de rentabilidad se ha convertido en una herramienta fundamental para determinar la capacidad financiera en el cumplimiento de compromisos operacionales (Acuña, 2016). Por otra parte, el sector industrial, una de las fuentes principales generadoras de ingreso a nivel nacional, dispone de una liquidez aceptable, debido a la gran variedad de materia prima que ofrece Ecuador para abastecer la rama manufacturera (INEC, 2018). La superintendencia de Compañías califica los rendimientos financieros de la industria manufacturero en 0.0164 veces, como resultado de la gestión administrativa- financiera (Superintendencia de compañías, valores y seguros, 2018). Así mismo, el mencionado índice sirve como medida en las finanzas administrativas a partir de la revisión de información económica, permitiendo valorar la rentabilidad que genera la empresa y estos, relacionarlo con los efectos del entorno interno y externo que se mantienen en evolución.

Uno de los ratios financieros es el margen bruto, que se obtiene del beneficio económico sobre los ingresos ordinarios (Martínez, 2005). Es decir, representa el beneficio de la empresa después de asumir los costos incurridos de la producción o de la venta. Por otra parte (Cheol \& Bruce G., 2007) expone que el margen operacional es un índice de margen utilizado para medir la estrategia de precios y la eficiencia operativa de una compañía. Es decir, muestra proporción recibida después de asumir los pagos causados por costos variables de producción (Angulo, 2012).

Dos razones financieras importantes que se utilizan para el análisis de los inversores y los acreedores incluyen el índice de rotación de activos totales y el margen de beneficio. La proporción de activos totales corresponde a la categoría de relaciones en la utilización de activos, que son importantes para medir la eficacia de la gestión. Margen de beneficio corresponde a la categoría de los ratios de rentabilidad, que mide periódicamente el éxito financiero de una empresa. La comprensión de estas dos relaciones puede ayudar a los administradores hacer los ajustes necesarios para mejorar el desempeño financiero de la compañía. Los inversores que entienden estas dos relaciones pueden tomar decisiones informadas acerca de la inversión en títulos financieros de una empresa. 


\section{Análisis de los inversores y los acreedores}

Acuña, (2016) propone el análisis de los inversores con los acreedores el proceso de medición ideal para determinar la eficiencia de los activos productivos para generación de ingresos. A continuación, se detallan los indicadores más usuales en temas financieros. Así mismo (León, 2010), plantea en su teoría financiera que el indicador de la utilidad después de impuesto en relación al total de activos sirve como herramienta de comparación con el costo promedio ponderado de capitales que permite la determinación de la generación de valor de la empresa. Cabe recalcar que es preferible maximizar el EVA en lugar de ver el RAN como la llave del éxito.

\section{Tabla 4}

Indicadores de Rotación de activos

\begin{tabular}{|c|c|c|}
\hline $\begin{array}{l}\text { Indicadores } \\
\text { Financieros }\end{array}$ & Fórmula & Evalúa \\
\hline $\begin{array}{l}\text { Rotación del Activo } \\
\text { Neto de Operación }\end{array}$ & $\frac{\text { Ventas Netas }}{\mathrm{AON}}$ & $\begin{array}{l}\text { La eficacia en la gestión de activos para } \\
\text { generar ventas. Cuanto más elevado sea el } \\
\text { valor de este ratio, mayor es la } \\
\text { productividad de los activos para generar } \\
\text { ventas y por tanto la rentabilidad del } \\
\text { negocio. }\end{array}$ \\
\hline $\begin{array}{c}\text { Rentabilidad del } \\
\text { Activo de Operación (ROA) }\end{array}$ & $\frac{\text { Utilidad Operacional }}{\mathrm{AON}}$ & $\begin{array}{l}\text { Mide la rentabilidad financiera de la } \\
\text { empresa, a partir de la comparación de la } \\
\text { utilidad obtenida en relación con la } \\
\text { inversión realizada. }\end{array}$ \\
\hline Rentabilidad Activos & $\begin{array}{l}\text { Utilidad neta } \\
\text { Total de activo }\end{array}$ & $\begin{array}{l}\text { Representa el margen neto por rotación } \\
\text { general del activo, es decir su utilización } \\
\text { logra obtener mejores resultados para la } \\
\text { toma de decisiones económicas en la } \\
\text { empresa. }\end{array}$ \\
\hline $\begin{array}{l}\text { Rentabilidad neta del } \\
\text { patrimonio (ROE) }\end{array}$ & $\begin{array}{l}\text { Utilidad neta } \\
\text { Patrimonio }\end{array}$ & $\begin{array}{l}\text { Mide la capacidad de generar beneficios } \\
\text { económicos de una empresa a partir de la } \\
\text { inversión realizada por los accionistas. }\end{array}$ \\
\hline
\end{tabular}

Elaboración propia, tomado del libro de Administración Financiera: fundamentos y su aplicación (León, 2010)

\section{Indicadores de endeudamiento}

Los indicadores de endeudamiento permiten analizar la capacidad de generar valor empresarial una vez deducidos sus pasivos u obligaciones, teniendo como finalidad la valoración del riesgo que asumen los dueños o accionistas frente a sus inversiones (Cheol \& Bruce G., 2007). Desde el punto de vista de los administradores de la empresa, el manejo del endeudamiento es todo un arte y su optimización depende, entre otras variables, de la situación financiera de la empresa en particular, de los márgenes de rentabilidad de la misma y del nivel de las tasas de interés vigentes en el mercado, teniendo siempre presente que trabajar con dinero prestado es bueno, siempre y cuando se logre una rentabilidad neta superior a los intereses que se debe pagar por ese dinero. A continuación, se pone a manifiesto los siguientes indicadores de endeudamiento:

\section{Endeudamiento del activo}

Este índice permite determinar el nivel de autonomía financiera. Cuando el índice es elevado indica que la empresa depende mucho de sus acreedores y que dispone de una 
limitada capacidad de endeudamiento, o lo que es lo mismo, se está descapitalizando y funciona con una estructura financiera más arriesgada. Por el contrario, un índice bajo representa un elevado grado de independencia de la empresa frente a sus acreedores (Cheol \& Bruce G., 2007). Para obtener el endeudamiento del activo se obtiene a partir del pasivo total en relación al activo total.

\section{Cobertura de intereses}

A través de este ratio se puede analizar la solvencia de la empresa en relación a las deudas con acreedores financieros (León, 2010). Es difícil establecer niveles óptimos de este ratio para cada empresa. Esto va a depender principalmente del sector económico y de las características que la diferencian a la empresa de su entorno. De todos modos, en ningún caso este ratio podría estar por debajo de 1 . De ser así. La empresa no sería capaz de hacer frente al pago de su deuda. Un ratio de 1,5 o superior, suele considerarse como una referencia adecuada de la capacidad de pago de la empresa tanto para el mercado, como para entidades de crédito. La fórmula de cálculo es: $\frac{\text { Utilidad Antes de Impuestos e Interéses }}{\text { Gastos Financieros }}$

\section{Cobertura del servicio de la deuda}

Se entiende por cobertura del servicio de la deuda, el disponer de flujo de caja suficiente, para afrontar el pago de los intereses generados de la deuda, más, su propio capital adeudado (Azofra, 2017). Contablemente son las partidas de gastos financieros (cuenta de resultados) y deuda a corto plazo (balance). El ratio de cobertura del servicio de la deuda (RCSD) compara el flujo de caja disponible en un período determinado, con el servicio de la deuda que se tiene que pagar, es decir devolución del importe del capital, más, el respectivo pago de los intereses. La fórmula es: $\frac{\text { EBITDA }}{\text { Gastos Financieros+Deudas a Corto Plazo }}$

\section{Flujo de caja libre}

(Azofra, 2017) considera el flujo de caja libre como la cantidad de dinero disponible por la organización para cubrir deuda o repartir dividendos, una vez se hayan deducido el pago a proveedores y las compras del activo fijo (construcciones, maquinaria, vehículos). Se obtienen a partir de las actividades operativas, una vez que se han satisfecho las necesidades de inversión, y, por tanto, pertenecen a aquellas personas interesadas en la gestión correcta de la organización, aquellos que han aportado recursos financieros a la organización. La fórmula es: Beneficio Neto + Amortización - Inversión en Activos Fijos - Inversión NOF.

\section{Problemática}

\section{Valoración actual de la inversión de las empresas manufactureras a nivel internacional}

El sector industrial ecuatoriano es uno de los más importantes, y con mayor diversidad o gama de productos, o materia prima con el que cuenta el país. Contribuyendo con el $12 \%$ del PIB (Producto Interno Bruto) de los últimos 16 años (Camara de Industrias; Boletin de Política Económica; Centro de Investigaciones Económicas; Espol, 2018). Permitiendo que la participación de las empresas ecuatorianas sea de 4.974 en el sector industrial, las cuales de ellas han tomado posición las " 25 primeras, estableciendo 
un 33,40\% de ingresos en relación al sector industrial". (Camara de Industrias; Boletin de Política Económica; Centro de Investigaciones Económicas; Espol, 2018).

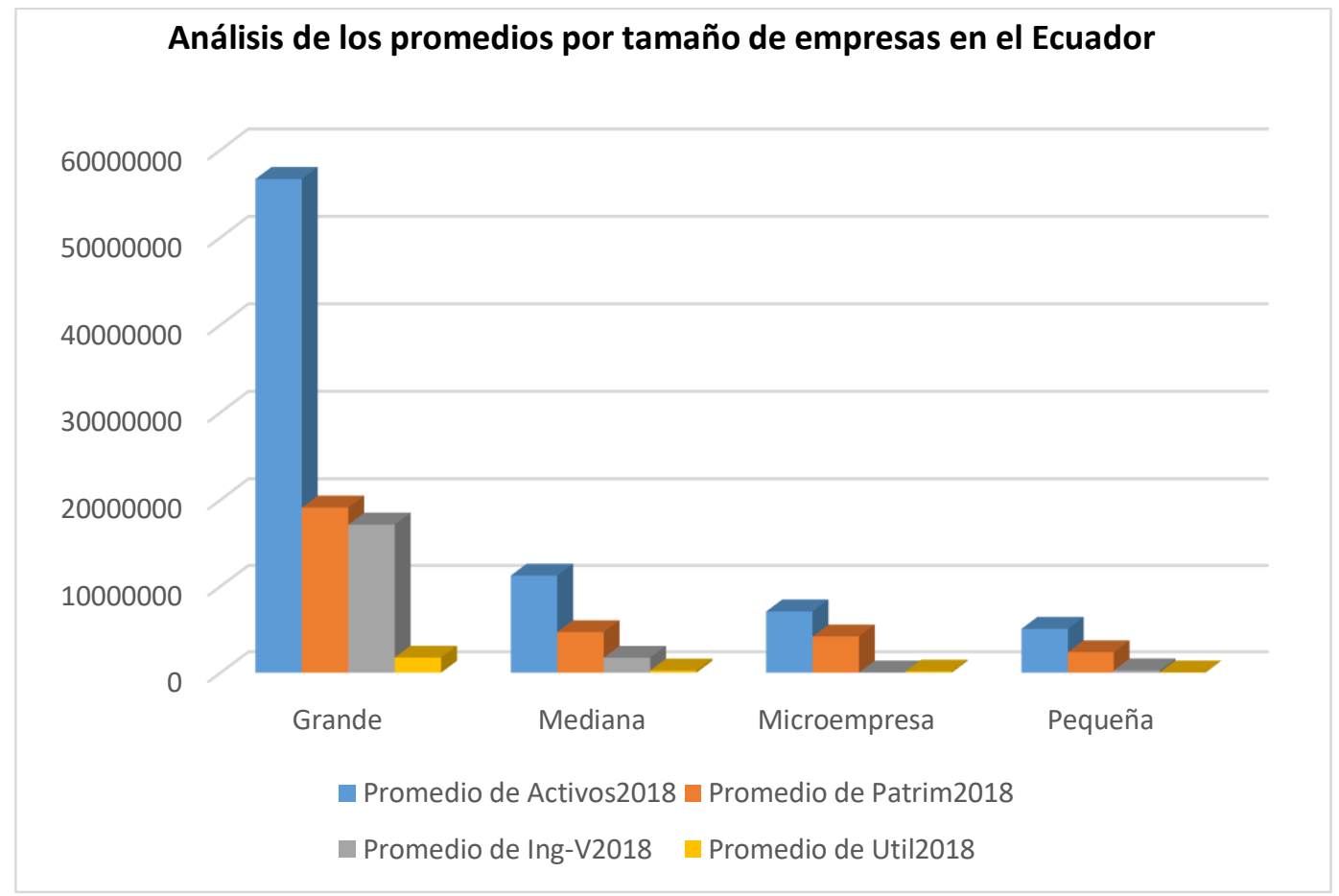

Ilustración 1.- Promedio de la estructura de capital de las empresas en el Ecuador

En el país, 13.694 grandes y medianas empresas movieron la economía en el 2017, más de $\$ 87.000$ millones en producción. Este conglomerado, en ese mismo año, invirtió \$ 3.317 millones en equipos y maquinarias y pagó \$17.779 millones en remuneraciones a 1'023.176 trabajadores; así lo sostiene el Instituto Nacional de Estadística y Censos (INEC) en los resultados de su último estudio "Encuesta Estructural Empresarial". En consecuencia del arduo desempeño y dinamismo en la economía generó más de 20.000 plazas de empleo en las diferentes áreas de la gran industria; considerando que la ciudad de Quito y Guayaquil ocupan la mayor participación en el mercado manufacturero (EKOS, 2018).

Dada las situaciones que se presentan en el entorno y a las exigencias de mercado que provoca la competitividad y el avance de la ciencia y tecnología Colineal Corporación Cía. Ltda., al ser considerada una de las empresas líderes en el negocio de fabricación y comercialización de muebles y complementos para la decoración del hogar en el mercado ecuatoriano, atraviesa por una situación de liquidez baja, debido a su mínima rotación de inventario; a pesar de la diversificación de sus productos, estos no cumplen ciertos parámetros de credibilidad, lo que ha generado un alto nivel de apalancamiento en relación a la adquisición de sus activos, poniendo en riesgo el incremento del costo amortizado que estos demandan. Así mismo, se pudo identificar a través de los estados financieros que quienes tienen mayor participación son los proveedores que los mismos socios. Sin embargo, a pesar de tener todas estas falencias la empresa no deja de ser una empresa líder en el mercado ecuatoriano, debido a la diversidad de productos que expone a nivel nacional y a sus iniciativas de éxito de la gestión empresarial.

Dentro de sus estratégicas, toma medidas de salvaguarda y de innovación que no afecte sus procesos productivos, como: la sustitución de importaciones de materia prima, principalmente de madera aserrada, con producto nacional, la implementación de 
estrategias enfocadas con el proveedor ya que ellos abastecen de ciertos productos que requiere la empresa, como son: muebles blancos, terminados, tapicería, forjados andinos, reparación, instalaciones, transporte y decoración de muebles. Además, implementan un sistema de comercialización innovador y de franquicias que genera participación activa en el mercado internacional y, sobre todo, el monitoreo permanente de los mercados domésticos e internacionales difundiendo sus productos en ferias nacionales, italianas, estadounidenses y españolas. La consideración de dichos elementos influye en aumentar el volumen de ventas y ser activo en la participación en el mercado con la finalidad de liderar el mismo, gracias a su amueblamiento único y original. Estas, a su vez, generan un aumento en la oferta y demanda, acelerando el movimiento comercial de muebles en el sector y de la economía ecuatoriana.

Una vez más se muestra la importancia de su participación económicamente activa en el área industrial. Al realizar análisis del comportamiento de ellas, se puede analizar puntos clave que permitan contribuir al desarrollo empresarial, enmarcadas en cómo mejorar la eficiencia, competitividad y, sobre todo, la sostenibilidad. Como se puede observar en la tabla 5, el factor de mantener la competitividad ha mejorado, permitiendo a varios países mantenerse en el ranking. Para ello, se hace mención a patrones que participan implícitamente en el cambio para la competitividad en los costos de fabricación. 1.- Bajo presión; 2.- Perdiendo terreno; 3.- Manteniendo la estabilidad y; por último, economías mundiales en ascensos.

Tabla 5

Patrones de Economía

\begin{tabular}{|c|c|c|c|c|c|c|}
\hline Bajo presión & $\begin{array}{l}\text { Países de bajo costo cuya } \\
\text { competitividad en deterioro es } \\
\text { impulsada por una amplia } \\
\text { gama de factores. }\end{array}$ & Brasil & China & $\begin{array}{l}\text { República } \\
\text { Checa }\end{array}$ & Polonia & Rusia \\
\hline $\begin{array}{l}\text { Perdiendo } \\
\text { terreno }\end{array}$ & $\begin{array}{l}\text { Tradicionalmente los países de } \\
\text { alto costo cuya competitividad } \\
\text { sigue deteriorándose, debido a la } \\
\text { debilidad productiva. }\end{array}$ & Australia & Bélgica & Francia & Italia & Suecia \\
\hline $\begin{array}{l}\text { Manteniendo } \\
\text { la estabilidad }\end{array}$ & $\begin{array}{l}\text { Países que mantienen más o } \\
\text { menos su competitividad relativa } \\
\text { frente a los líderes mundiales. }\end{array}$ & India & Indonesia & $\begin{array}{l}\text { Países } \\
\text { Bajos }\end{array}$ & $\begin{array}{l}\text { Reino } \\
\text { Unido }\end{array}$ & \\
\hline $\begin{array}{l}\text { Economías } \\
\text { mundiales en } \\
\text { ascenso }\end{array}$ & $\begin{array}{l}\text { Mejora de competitividad en } \\
\text { comparación con otros, debido al } \\
\text { crecimiento moderado de sus } \\
\text { salarios, productividad } \\
\text { sustentable, las ventajas de } \\
\text { costos de energía. }\end{array}$ & & México & $\begin{array}{l}\text { Estados } \\
\text { Unidos }\end{array}$ & & \\
\hline
\end{tabular}

Elaborado por: Autoras

Fuente: The Boston Consulting Group

Con toda esta información acerca del sector industrial- manufacturero de los años 2017-2018, se puede conocer el entorno en el que se desenvolvió Colineal Corporation en este periodo, y el porqué de sus variaciones económicas.

\section{Metodología}

Para el desarrollo del tema propuesto, se consideró una metodología con enfoque cuantitativo transversal, debido al estudio que se realizó de las cifras económicas-financieras 
presentadas por la superintendencia de compañías del Ecuador; las mismas que se comparan y analizan en dos períodos consecutivos. Además, este estudio se complementa en análisis documental, que sustentan teóricamente el aporte estratégico que representa el análisis financiero en las decisiones empresariales; las mismas, se argumentan con teorías de autores sobre los temas financieros. Por otra parte, esta investigación es de tipo explicativalongitudinal, puesto que explica el comportamiento financiero en relación a factores determinantes del mercado interno y crecimiento económico que logra el sector manufacturero, permitiendo evaluar los aspectos claves de gestión de operación, inversión y financiamiento que faciliten propuestas idóneas para fortalecer la participación en el mercado y alcanzar la sostenibilidad.

Así mismo, para el desarrollo del análisis financiero se utilizó la técnica de la observación para revisar y comparar los datos contables de la empresa Colineal Corporation CIA Ltda. en los periodos 2017 - 2018, mediante el uso de herramientas de Excel se aplicaron las fórmulas financieras, como: ratios, índices y otros indicadores junto con información adicional, principalmente relacionada con contexto económico y competitivo en el que se desenvuelve la organización. A continuación, se procedió a realizar el análisis financiero para conocer su estado actual para la toma de decisiones en la gestión operativa de la compañía.

\section{Resultados}

Como resultado de la revisión, análisis y comparación de los datos que reportan los estados financieros de Colineal Corporation Cía. Ltda. del año 2017 y 2018, se presenta el análisis financiero sobre tres conceptos básicos, los cuales son: liquidez, el mismo que permite medir la capacidad que tiene la empresa para hacer frente a sus necesidades de recursos y cumplir con sus deudas de corto plazo; en el cual se observan variables como: endeudamiento, activo circulante, periodo de maduración, rotación, entre otros. Por otra parte, el indicador de rentabilidad, que muestra el valor que representa la empresa en relación a sus inversiones; mostrando además su composición, calidad, evolución y proyección. Por último, el indicador solvencia que proporciona datos que sirven para determinar el nivel de endeudamiento a largo plazo y tomar decisiones de inversión; en este caso observamos variables como: endeudamiento a largo plazo, patrimonio, fuentes de financiación, entre otros.

Los estados financieros proporcionados por la superintendencia de compañías muestran las cifras en millones de dólares concretas, recopiladas, clasificadas y; se hace posible el análisis financiero de la empresa, tomado de un estudio de la organización a lo largo del tiempo y teniendo en cuenta factores internos y externos del sujeto como objeto de análisis.

\section{Índices de liquidez}

Calculando el índice de capital de trabajo, se puede notar que la empresa tiene dinero disponible, producto de su capital de trabajo de USD \$33.927,38 en el 2017 para cubrir las obligaciones que surgen en el desarrollo normal de sus actividades económicas, se puede observar que para el año 2018 dicho capital tiene una disminución del -4,75\%, que representó USD \$747.557,61 en el año 2018. 
Una vez la empresa cancele el total de sus obligaciones corrientes en el año 2017 le quedarían 33.927,38 dólares para atender el resto de las obligaciones que surgen en el normal desarrollo de su actividad económica, lo cual es muy poco, teniendo en cuenta los montos económicos que maneja la empresa; situación que para el año 2018 se agrava aún más, pues dicho capital de trabajo es negativo; es decir, la empresa no podría atender sus obligaciones corrientes en su totalidad.

\section{Tabla 6}

Análisis del Capital de Trabajo (en miles de dólares)

\begin{tabular}{lrrr}
\hline Rubros & $\mathbf{2 0 1 7}$ & $\mathbf{2 0 1 8}$ & Variación \\
\hline Activo Corriente & $20^{\prime} 563.699,30$ & $19^{\prime} 731.311,46$ & $-832.387,84$ \\
Pasivo Corriente & $20^{\prime} 529.771,92$ & $20^{\prime} 4444941,69$ & $-84.830,23$ \\
\hline Capital de trabajo Neto & $\mathbf{\$ 3 3 . 9 2 7 , 3 8}$ & $\mathbf{( \$ 7 1 3 . 6 3 0 , 2 3 )}$ & \\
\hline \multicolumn{4}{c}{ Elaborado por: Los autores }
\end{tabular}

Fuente: Estados Financieros de Colineal Corporation Cía. Ltda., tomado de (Superintendencia de Compañías, valores y seguros , 2018)

\section{Razón corriente}

La empresa tuvo en el año 2017 un indicador de \$1,02 dólares; es decir, la empresa puede respaldar sus obligaciones en el corto plazo, como: sueldos y salarios, beneficios a empleados, proveedores, obligaciones fiscales, con el IESS, este índice a pesar de estar levemente por encima a 1 es considerable saludable, pero para el año 2018 el indicador baja a 0,965 centavos de dólar debido a la disminución que hubo en el activo dado por los efectivos y equivalentes de efectivo y activos financieros, disminuyendo su liquidez, lo que significa que no podría respaldar sus obligaciones en el corto plazo en su totalidad.

La variación de disminución entre el año 2017 y 2018 que generó el -0.037 dólares puede ser perjudicial para la empresa, ya que su disponibilidad puede resultar real; sin embargo, no significa que estos valores reflejen flujos de efectivo. Para lo cual se necesita el análisis comparativo de la rotación del inventario.

\section{Tabla 7}

Análisis de Razón corriente (en miles de dólares)

\begin{tabular}{lll}
\hline Cuentas & $\mathbf{2 0 1 7}$ & $\mathbf{2 0 1 8}$ \\
\hline Activo Corriente & $20^{\prime} 563.699,30$ & 19731311.46 \\
(/) Pasivo Corriente & $20^{\prime} 529.771,92$ & 20444941.69 \\
\hline Total & $\mathbf{1 . 0 0 2}$ & $\mathbf{0 . 9 6 5}$
\end{tabular}

Elaborado por: Los autores

Fuente: Estados Financieros de Colineal Corporation Cía. Ltda., tomado de (Superintendencia de Compañías, valores y seguros, 2018)

\section{Prueba ácida}

Se puede observar que la empresa tiene la necesidad de atender todas sus obligaciones corrientes sin necesidad de liquidar y vender sus inventarios. En el año 2017 no alcanzaría a cubrir sus obligaciones y tendría que liquidar sus inventarios para poder cumplir; así mismo, podemos observar que en el año 2018 este indicador incluso tiene una leve disminución, lo 
que dificultaría aún más poder atender sus obligaciones corrientes sin necesidad de vender sus inventarios. La empresa depende directamente de la venta de sus inventarios para poder atender sus obligaciones corrientes. Lo ideal sería que por cada dólar que la empresa debe, se genere un dólar para cubrir deudas en independencia de los inventarios.

Tabla 8

Análisis de Prueba ácida (en miles de dólares)

\begin{tabular}{lll}
\hline Cuentas & $\mathbf{2 0 1 7}$ & $\mathbf{2 0 1 8}$ \\
\hline Activo Corriente & $20^{\prime} 563.699,30$ & $19^{\prime} 731.311,46$ \\
(-) Inventarios & $8^{\prime} 959.137,19$ & $8^{\prime} 603.524,35$ \\
(/) Pasivo Corriente & $20^{\prime} 529.771,92$ & $20^{\prime} 444.941,69$ \\
\hline Total & $\mathbf{0 . 5 6 5}$ & $\mathbf{0 . 5 4 4}$ \\
\hline
\end{tabular}

Elaborado por: Los autores

Fuente: Estados Financieros de Colineal Corporation Cía. Ltda., tomado de (Superintendencia de Compañías, valores y seguros , 2018)

\section{Rotación de inventarios}

La empresa en el año 2017 tiene una rotación de su inventario cada 153.42 días, o de 2.35 veces en el año, lo que significa que tiene una rotación de inventario muy lenta, considerando que a menor rotación mayor es el costo de almacenamiento del inventario ya que el capital de trabajo invertido por los inventarios es mayor.

Para el año 2018 vemos que el inventario rota cada 147.09 días o 2.45 veces en el año; si bien, hay una pequeña mejoría de rotación de 0,1 veces, en el 2018, ésta aún sigue siendo demasiado lenta, para los estándares que manejan algunos autores que es de 6 veces en el año, y por consiguiente, se considera que habría que mejorar la estrategia de ventas para que el inventario pueda ser vendido más rápido.

Tabla 9

Análisis de Rotación de inventario (en miles de dólares)

\begin{tabular}{lll}
\hline Cuentas & $\mathbf{2 0 1 7}$ & $\mathbf{2 0 1 8}$ \\
\hline Inventarios & 8959137.19 & 8603524.35 \\
(/) Costo de Ventas & 21023173.27 & 21057649.29 \\
$(x) 360$ días & 360 días & 360 días \\
\hline Total & $\mathbf{1 5 3 . 4 2}$ días & $\mathbf{1 4 7 . 0 9}$ días \\
\hline Veces & & $21^{\prime} 057.649 .29$ \\
\hline Costo de Ventas & $21^{\prime} 023.173 .27$ & 8603524.35 \\
(/) Inventarios & $8^{\prime} 959.137 .19$ & $\mathbf{2 . 4 5}$ veces
\end{tabular}

Elaborado por: Los autores

Fuente: Estados Financieros de Colineal Corporation Cía. Ltda., tomado de (Superintendencia de Compañías, valores y seguros , 2018)

\section{Rotación de cuentas por cobrar}

La rotación de las cuentas por en la empresa Colineal en el año 2017 fue de 9.88 veces, es decir, cada 36.45 días lo que demuestra que hubo eficiencia en el manejo de la cartera, teniendo en cuenta que normalmente las empresas manejan los créditos de 30 a 60 días de plazo. Para el año 2018, incluso fueron mucho más eficientes porque en promedio las 
cuentas por cobrar rotaron 10,67 veces, es decir, cobraron cada 33.73 días, lo que muestra una reducción de aproximadamente casi 3 días. En este sentido la empresa no tiene problemas con el manejo de la cartera.

\section{Tabla 10}

Análisis de Rotación de cuentas por cobrar (en miles de dólares)

\begin{tabular}{lll}
\hline Cuentas & $\mathbf{2 0 1 7}$ & $\mathbf{2 0 1 8}$ \\
\hline Cuentas por Cobrar & $4^{\prime} 485.527 .20$ & $4^{\prime} 219.925 .64$ \\
(/) Ventas Netas & $44^{\prime} 303.140 .55$ & $45^{\prime} 033.628 .9$ \\
(x) 360 días & 360 días & 360 días \\
\hline Total & $\mathbf{3 6 . 4 5}$ días & $\mathbf{3 3 . 7 3 ~ d i ́ a s ~}$ \\
\hline Rotación de cuentas por cobrar & & $45^{\prime} 033.628 .90$ \\
\hline Ventas Netas & $44^{\prime} 303.140 .55$ & $4^{\prime} 219.925 .64$ \\
(/) Cuentas por Cobrar & $4^{\prime} 485.527 .20$ & $\mathbf{1 0}^{\prime 0.67}$ veces
\end{tabular}

\section{Elaborado por: Los autores}

Fuente: Estados Financieros de Colineal Corporation Cía. Ltda., tomado de (Superintendencia de Compañías, valores y seguros , 2018)

\section{Rotación de proveedores}

La rotación de sus cuentas por pagar a proveedores es de 8,92 veces, que significa que tiene 40.34 días de plazo aproximado en el año 2017 y de 8,75 veces o de 41.15 días de plazo aproximado en el 2018; al cumplir con las deudas propias de la actividad operativa, se ve disminuido el disponible de efectivo. Las deudas se originan por la adquisición de materia prima, materiales indirectos y varios costos indirectos de fabricación que forman parte del inventario. Para medir la eficiencia en el manejo de las cuentas por pagar, se debe comparar con la rotación de cartera y los resultados muestran que tanto en el año 2017 como el 2018 la rotación de proveedores es mayor que la rotación de cartera, lo que es correcto porque se cobra cada 36.45 en el año 2017 y se paga cada 40.34 días, mientras que en el 2018 se cobra cada 33.73 días y se paga cada 41.15 días. Se concluye que la empresa tuvo el tiempo necesario para cumplir con el pago a sus proveedores, aunque es limitado ya que dispone de unos cuantos días de diferencia.

\section{Tabla 11}

Análisis de Rotación de Proveedores (en miles de dólares)

\begin{tabular}{lll}
\hline Cuentas & $\mathbf{2 0 1 7}$ & $\mathbf{2 0 1 8}$ \\
\hline Cuentas por Pagar & $1^{\prime} 697.964,30$ & $1^{\prime} 787.123,47$ \\
(/) Compras Netas & $15^{\prime} 152.854,08$ & $15^{\prime} 635.009,10$ \\
(x) 360 días & 360 días & 360 días \\
\hline Total & $\mathbf{4 0 . 3 4}$ días & $\mathbf{4 1 . 1 5}$ días \\
\hline Rotación de proveedores en veces & & $15^{\prime} 635.009,10$ \\
\hline Compras Netas & $15^{\prime} 152.854,08$ & $1^{\prime} 787.123,47$ \\
(/) Cuentas por Pagar & $1^{\prime} 697.964,30$ & $\mathbf{8 . 7 5}$ veces \\
\hline Total & $\mathbf{8 . 9 2}$ veces &
\end{tabular}

Elaborado por: Los autores

Fuente: Estados Financieros de Colineal Corporation Cía. Ltda., tomado de (Superintendencia de Compañías, valores y seguros , 2018) 


\section{Ciclo Operativo}

La empresa tiene un ciclo operativo en el año 2017 de 189.87 días, si comparamos con el año 2018 se muestra que baja a 180.82 días; lo que significa que el flujo operativo es demasiado alto, pues el ciclo de pagos se da cada 40.34 días en el año 2017 y 41.15 días en el año 2018, lo cual, deja un plazo mínimo para operar. Es decir, la rotación del inventario que es demasiado elevada en número de días, por lo tanto, es necesario mejorar dicha rotación, de lo contrario se necesita dinero para financiar el resto del ciclo operativo que en el 2017 fue de 149.50 días y en el año 2018 de 139.67 días. Por lo que se recomienda disminuir la rotación de proveedores, aumentando el plazo de pago, para dejar así más días para operar.

Tabla 12

\begin{tabular}{lll}
\multicolumn{3}{c}{ Análisis del Ciclo Operativo (en miles de dólares) } \\
\hline Cuentas & $\mathbf{2 0 1 7}$ & $\mathbf{2 0 1 8}$ \\
\hline Días de Inventario & 153.42 días & 147.09 días \\
(+) Días Cuentas por Cobrar & 36.45 días & 33.73 días \\
Ciclo Operativo & $\mathbf{1 8 9 . 8 7}$ días & $\mathbf{1 8 0 . 8 2}$ días \\
Días de Cuentas por Pagar & 40.34 días & 41.15 días \\
(-) Ciclo de Pagos & $\mathbf{4 0 . 3 4}$ días & $\mathbf{4 1 . 1 5}$ días \\
Total & $\mathbf{1 4 9 . 5 0}$ días & $\mathbf{1 3 9 . 6 7}$ días \\
\hline
\end{tabular}

Elaborado por: Los autores

Fuente: Estados Financieros de Colineal Corporation Cía. Ltda., tomado de (Superintendencia de Compañías, valores y seguros , 2018)

\section{Capital de trabajo operativo (KTO)}

En el año 2017 la empresa muestra un capital de trabajo operativo de 13`444.664,39 millones de dólares, mientras que en el año 2018 tuvo 12823.449,99 millones de dólares, es decir, hubo una disminución de 621.214,40 mil dólares, producto de la disminución tanto en inventarios como en las cuentas por cobrar, representando el $4.6 \%$ menos de capital operativo, lo que no es significativamente representativo, sin embargo, puede hacer frente a las obligaciones que tiene a corto plazo.

Tabla 13

Análisis del Capital de Trabajo Operativo (en miles de dólares)

\begin{tabular}{lll}
\hline Cuentas & $\mathbf{2 0 1 7}$ & $\mathbf{2 0 1 8}$ \\
\hline Inventarios & $8^{\prime} 959.137,19$ & $8^{\prime} 603.524,35$ \\
(+) Cuentas por Cobrar & $4^{\prime} 485.527,20$ & $4^{\prime} 219.925,64$ \\
\hline Total & $\mathbf{1 3}^{\prime} \mathbf{4 4 4 . 6 6 4 , 3 9}$ & $\mathbf{1 2}^{\prime} \mathbf{8 2 3 . 4 4 9 , 9 9}$ \\
\hline
\end{tabular}

Elaborado por: Los autores

Fuente: Estados Financieros de Colineal Corporation Cía. Ltda., tomado de (Superintendencia de Compañías, valores y seguros , 2018)

\section{Capital de trabajo neto operativo (KTNO)}

Haciendo una comparación del capital neto operativo de la empresa vemos que cuenta con la solvencia suficiente en inventarios y cuentas por cobrar, para hacer frente a sus obligaciones con los proveedores a corto plazo; pues en el año 2017 le quedó 11746700.09 millones de dólares, esto a pesar que en el año 2018 hubo una disminución de 710373.57 mil dólares, en el capital de trabajo neto operativo, lo que en términos porcentuales representó el 
$6.05 \%$, pero esto no representa ningún riesgo para la solvencia operativa de la empresa para cumplir sus obligaciones con los acreedores.

Tabla 14

Análisis del Capital de Trabajo Neto Operativo (en miles de dólares)

\begin{tabular}{lll}
\hline Cuentas & $\mathbf{2 0 1 7}$ & $\mathbf{2 0 1 8}$ \\
\hline Inventarios + Cuentas por Cobrar & $13^{\prime} 4444.664,39$ & $1^{\prime} 823.449,99$ \\
(-) Cuentas por Pagar & $1^{\prime} 697.964,30$ & $1^{\prime} 787.123,47$ \\
\hline Total & $\mathbf{1 1}^{\prime} \mathbf{7 4 6 . 7 0 0 , 0 9}$ & $\mathbf{1 1}^{\prime} \mathbf{0 3 6 . 3 2 6 , 5 2}$ \\
\hline
\end{tabular}

Elaborado por: Los autores

Fuente: Estados Financieros de Colineal Corporation Cía. Ltda., tomado de (Superintendencia de Compañías, valores y seguros , 2018)

\section{EBITDA}

Este análisis muestra la capacidad de la empresa para generar una utilidad operativa, sin financiamiento bancario. En el año 2017 fue de 3`418.047,09 millones de dólares y en el 2018 fue de 4’194.930,36 millones de dólares, lo que en principio puede parecer bueno; pero realizando un análisis un poco más a fondo no es así, pues estos resultados comparados con el total de ventas solo representan el $0.08 \%$ y $0.09 \%$; una utilidad muy baja si se considera que las tasas de interés por financiamiento están por alrededor del $14 \%$, se debería buscar generar utilidad por sobre esa tasa de interés.

Tabla 15

Análisis del EBITDA (en miles de dólares)

\begin{tabular}{lll}
\hline CUENTAS & $\mathbf{2 0 1 7}$ & $\mathbf{2 0 1 8}$ \\
\hline Utilidad Operativa & $3{ }^{\prime} 226.367,32$ & $3^{\prime} 979.770,90$ \\
(+) Depreciaciones & $191.679,77$ & $215.159,46$ \\
\hline TOTAL & $\mathbf{3}^{\prime} \mathbf{4 1 8 . 0 4 7 , 0 9}$ & $\mathbf{4}^{\prime} \mathbf{1 9 4 . 9 3 0 , 3 6}$ \\
\hline
\end{tabular}

Elaborado por: Los autores

Fuente: Estados Financieros de Colineal Corporation Cía. Ltda., tomado de (Superintendencia de Compañías, valores y seguros, 2018)

\section{Análisis de rentabilidad, margen bruto}

Se puede observar que en el año 2017 los ingresos operacionales netos generan un $51,86 \%$ de utilidad Bruta; es decir, por cada dólar vendido se generó 0,52 centavos de utilidad. Para el año 2018 un aumento del 3,4\%, datos que muestran una utilidad de 0,55 centavos para cubrir los gastos operacionales y no operacionales por cada dólar vendido.

Tabla 16

Análisis del Margen Bruto (en miles de dólares)

\begin{tabular}{lll}
\hline Rubro & $\mathbf{2 0 1 7}$ & $\mathbf{2 0 1 8}$ \\
\hline Utilidad bruta & $23 ` 279.967,28$ & $23 ` 975.979,63$ \\
Ventas netas & $44 \times 892.370,85$ & $433390.832,27$ \\
Margen de utilidad & $51,86 \%$ & $55,26 \%$ \\
\hline
\end{tabular}

Elaborado por: Los autores

Fuente: Estados Financieros de Colineal Corporation Cía. Ltda., tomado de (Superintendencia de Compañías, valores y seguros , 2018) 


\section{Margen operacional}

Tabla 17

Análisis del Margen Operacional (en miles de dólares)

\begin{tabular}{lll}
\hline \multicolumn{1}{c}{ Rubro } & \multicolumn{1}{c}{$\mathbf{2 0 1 7}$} & \multicolumn{1}{c}{$\mathbf{2 0 1 8}$} \\
\hline Utilidad operacional & 3226367.32 & 3979770.90 \\
Ventas netas & 44892370,85 & 43390832,27 \\
Margen Operacional & $7,18 \%$ & $9,17 \%$ \\
\hline
\end{tabular}

Elaborado por: Los autores

Fuente: Estados Financieros de Colineal Corporation Cía. Ltda., tomado de (Superintendencia de Compañías, valores y seguros , 2018)

La compañía para el año 2018 generó una utilidad operacional de 9,17\%, en comparación con el año 2017 que generó el 7,18\%, evidenciándose un incremento del 1,99\% en la utilidad operacional, pero esto debido a un aumento de la utilidad operacional del $18,93 \%$.

\section{Margen neto}

Este margen neto revela que las ventas en el 2018 en comparación con el año 2017 tuvieron una disminución, pero el cálculo refleja la capacidad de la organización para aumentar su utilidad a pesar de esto, ya que para el 2018, el margen neto aumentó en 1,83\%, es decir, que Colineal está tratando de maximizar su utilidad eficientemente por medio del control de costos, y no tanto por el nivel de sus ventas.

Tabla 18

Análisis del Margen Neto (en miles de dólares)

\begin{tabular}{lll}
\hline Rubro & $\mathbf{2 0 1 7}$ & $\mathbf{2 0 1 8}$ \\
\hline Utilidad neta & $655.516,20$ & 1 `426.525,01 \\
Ventas netas & 44 ` $892.370,85$ & 43 `390.832,27 \\
Margen Neto & $\mathbf{1 , 4 6 \%}$ & $\mathbf{3 , 2 9 \%}$ \\
\hline
\end{tabular}

Elaborado por: Los autores

Fuente: Estados Financieros de Colineal Corporation Cía. Ltda., tomado de (Superintendencia de Compañías, valores y seguros , 2018)

\section{Rotación del activo neto de operación}

Al realizar el cálculo respectivo para cada año, estos muestran que por cada dólar invertido en el activo operativo en el año 2017 la empresa genera 1,75 dólares en ventas. Al ser un valor alto, estas se acumulan a lo largo del tiempo. En el año 2018 la empresa genera 1,73 dólares en ventas. Esta variación de disminución es dada por la venta de activos productivos para la empresa y la evidente disminución de las ventas netas.

Tabla 19

Análisis del Rotación del Activo Neto de Operación (en miles de dólares)

\begin{tabular}{lll}
\hline Rubro & $\mathbf{2 0 1 7}$ & $\mathbf{2 0 1 8}$ \\
\hline Ventas netas & $44^{`} 892.370,85$ & $43^{` 3} 30.832,27$ \\
AON & $25 ` 661.841,35$ & $25066.627,14$ \\
Rotación AON & 1,75 & 1,73 \\
\hline
\end{tabular}

Elaborado por: Los autores

Fuente: Estados Financieros de Colineal Corporation Cía. Ltda., tomado de (Superintendencia de Compañías, valores y seguros , 2018) 


\section{Rotación general del activo}

En la siguiente tabla se puede observar en el año 2017 de cada dólar invertido del total de activos la empresa genera $\$ 0,85$ centavos en ventas netas. En el año 2018 generó \$0,83 centavos en ventas netas, evidenciando una ligera disminución del margen de utilidad, esto debido a una disminución del total de activos, es decir, el rendimiento que proporcionan los activos totales cubre las inversiones en propiedad, planta y equipo. Ventas que se producen gracias a la misma inversión realizada.

\section{Tabla 20}

Análisis de Rotación General del Activo (en miles de dólares)

\begin{tabular}{lll}
\hline Rubro & $\mathbf{2 0 1 7}$ & $\mathbf{2 0 1 8}$ \\
\hline Ventas netas & 44892370,85 & 43390832,27 \\
\hline Total de activos & 52677860,95 & 52326727,97 \\
\hline Margen de utilidad & 0,85 & 0,83 \\
\hline
\end{tabular}

Elaborado por: Los autores

Fuente: Estados Financieros de Colineal Corporation Cía. Ltda., tomado de (Superintendencia de Compañías, valores y seguros , 2018)

\section{Rentabilidad del Activo de Operación (ROA) versus Rentabilidad Activos Netos (RAN)}

La empresa obtiene un ROA en el año 2017de 12,57\%, la misma, muestra la capacidad generadora de utilidades; para el año 2018 tiene una capacidad mayor del 15,88\%; con un incremento de 3,31\% de variación; Pero, a pesar de esta mejoría la empresa aún coloca los recursos de la empresa dentro de la actividad en inversiones de activo, sacrificando su liquidez.

\section{Tabla 21}

Análisis del ROA (en miles de dólares)

\begin{tabular}{lll}
\hline Rubro & $\mathbf{2 0 1 7}$ & $\mathbf{2 0 1 8}$ \\
\hline Utilidad Operacional & 3226367.32 & 3979770.90 \\
AON & 25661841,35 & 25066627,14 \\
Rentabilidad ROA & $12,57 \%$ & $15,88 \%$ \\
\hline
\end{tabular}

Elaborado por: Los autores

Fuente: Estados Financieros de Colineal Corporation Cía. Ltda., tomado de (Superintendencia de Compañías, valores y seguros , 2018)

La empresa en el año 2017 genera una capacidad de producir de $1.24 \%$, después de ingresos, egresos no operacionales e impuestos sobre los activos totales. En el año 2018 tienen una capacidad de $2,73 \%$, evidenciándose una variación positiva de $1.49 \%$ de beneficios productivos que reflejan los activos ante la rentabilidad de la empresa sobre las ventas.

Tabla 22

Análisis de Rentabilidad de Activos Netos (en miles de dólares)

\begin{tabular}{lll}
\hline Rubro & $\mathbf{2 0 1 7}$ & $\mathbf{2 0 1 8}$ \\
\hline Utilidad neta & 655516,20 & 1426525,01 \\
Total de activos & 52677860,95 & 52326727,97 \\
RAN & $\mathbf{1 , 2 4 \%}$ & $\mathbf{2 , 7 3 \%}$ \\
\hline
\end{tabular}

Elaborado por: Los autores

Fuente: Estados Financieros de Colineal Corporation Cía. Ltda., tomado de (Superintendencia de Compañías, valores y seguros, 2018) 


\section{Rentabilidad Fiscal del Patrimonio (RFPt)}

En el año 2017 hubo rentabilidad fiscal del patrimonio de 7,4\% generada del patrimonio; sin embargo, en el año 2018 aumenta hasta el 11,7\%. Es decir, por cada dólar invertido se está logrando un aumento en la utilidad operacional del 4,3\%. Es decir, existiera mayor variación en el incremento del patrimonio si el inversionista financiará la totalidad de los activos.

\section{Tabla 23}

Análisis de Rentabilidad Fiscal del Patrimonio (en miles de dólares)

\begin{tabular}{lll}
\hline \multicolumn{1}{c}{ Rubro } & $\mathbf{2 0 1 7}$ & $\mathbf{2 0 1 8}$ \\
\hline Utilidad antes de impuesto & $1^{\prime} 387.383,37$ & $2^{\prime} 180.493,35$ \\
Patrimonio del año anterior & $18^{\prime} 654.324,78$ & $18^{\prime} 602.410,54$ \\
RFPt & $7,4 \%$ & $11,7 \%$ \\
\hline
\end{tabular}

Elaborado por: Los autores

Fuente: Estados Financieros de Colineal Corporation Cía. Ltda., tomado de (Superintendencia de Compañías, valores y seguros , 2018)

\section{Análisis ROA frente al RFPt}

Al comparar la rentabilidad fiscal del patrimonio con la rentabilidad de activos operacionales, se muestran datos que no representan generación de valor, ya que el valor de la rentabilidad de activos operacionales (ROA) es mayor a la rentabilidad del accionista; es decir, existe menor riesgo de inversión y por ende menor rendimiento financiero para el accionista.

\section{Tabla 24}

Análisis ROA frente al RFPt (en miles de dólares)

\begin{tabular}{lll}
\hline Rubro & $\mathbf{2 0 1 7}$ & $\mathbf{2 0 1 8}$ \\
\hline ROA & $12,57 \%$ & $15,88 \%$ \\
RFPt & $7,4 \%$ & $11,7 \%$ \\
\hline
\end{tabular}

Elaborado por: Los autores

Fuente: Estados Financieros de Colineal Corporation Cía. Ltda., tomado de (Superintendencia de Compañías, valores y seguros , 2018)

\section{Rentabilidad neta del patrimonio}

En el periodo 2018 el patrimonio tiene un incremento en relación al 2017 con el 3\%., es decir, por cada dólar invertido se está logrando una utilidad neta de 6,5\% en el 2018, lo cual, no representa una buena capacidad de generar beneficios con el dinero proporcionado por los accionistas.

Tabla 25

Análisis de Rentabilidad Neta del Patrimonio (en miles de dólares)

\begin{tabular}{lll}
\hline Rubro & $\mathbf{2 0 1 7}$ & $\mathbf{2 0 1 8}$ \\
\hline Utilidad neta & $655.516,20$ & 1 4 $426.525,01$ \\
Patrimonio & $18 ` 602.410,54$ & $21\urcorner 753.072,29$ \\
RNPt & $\mathbf{3 , 5 \%}$ & $\mathbf{6 , 5 \%}$ \\
\hline
\end{tabular}

Elaborado por: Los autores

Fuente: Estados Financieros de Colineal Corporation Cía. Ltda., tomado de (Superintendencia de Compañías, valores y seguros , 2018) 


\section{Indicadores de endeudamiento}

El nivel de endeudamiento del activo de la empresa Colineal en el año 2017 fue de 0.65 centavos de dólar; es decir, de cada dólar que se invirtió en activos el $65 \%$ lo financiaron los acreedores de la empresa, quienes tienen mayor participación que los mismos socios, lo que no es recomendable; si se compara con el año 2018 este porcentaje se reduce a 0.58 centavos de dólar lo que es positivo, aunque todavía sigue siendo demasiado elevado para los estándares recomendados por algunos autores que es del 0.50 como máximo, se recomienda seguir reduciendo los niveles de deuda con los acreedores y aumentar la participación de los acreedores.

Tabla 26

Análisis de Nivel de endeudamiento (en miles de dólares)

\begin{tabular}{cll}
\hline CUENTAS & $\mathbf{2 0 1 7}$ & $\mathbf{2 0 1 8}$ \\
\hline Pasivo Total & 34075.450 .41 & $30 ` 573.655 .68$ \\
(/) Activo Total & $52 ` 677.860 .95$ & $52 ` 326.727 .97$ \\
\hline TOTAL & $\mathbf{0 . 6 5}$ & $\mathbf{0 . 5 8}$ \\
\hline
\end{tabular}

Elaborado por: Los autores

Fuente: Estados Financieros de Colineal Corporation Cía. Ltda., tomado de (Superintendencia de Compañías, valores y seguros , 2018)

\section{Cobertura de interés}

La empresa tiene en el año 2017 un indicador de cobertura de intereses de 1.83 dólares; es decir, que, si tiene una muy buena capacidad de pago de intereses de deuda, considerando que el estándar recomendado es 1, incluso en el año 2018 este indicador mejora y se ubica en 2.50 dólares, por lo que la empresa no tiene ningún inconveniente en este indicador.

Tabla 27

Análisis de Cobertura de interés (en miles de dólares)

\begin{tabular}{lll}
\hline Cuentas & $\mathbf{2 0 1 7}$ & $\mathbf{2 0 1 8}$ \\
\hline Utilidad Antes de Impuestos e Intereses & $2 ` 922.029 .92$ & $3 ` 535.267 .01$ \\
(/) Gastos Financieros & $1 ` 594.151 .59$ & $1 ` 414.484 .61$ \\
\hline Total & $\mathbf{1 . 8 3}$ & $\mathbf{2 . 5 0}$
\end{tabular}

Elaborado por: Los autores

Fuente: Estados Financieros de Colineal Corporation Cía. Ltda., tomado de (Superintendencia de Compañías, valores y seguros , 2018)

\section{Cobertura del servicio de la deuda}

La empresa de estudio, tanto en el año 2017 como en el 2018, no cuenta con el flujo de caja suficiente o con una solvencia económica para cumplir con el pago de sus obligaciones financieras más los respectivos intereses; pues estos indicadores se encuentran por debajo de 1 que es el estándar que manejan la mayoría de los analistas financieros. Los resultados financieros muestran que la solvencia de la empresa se encuentra en la inversión en activos de operación. 
Tabla 28

Análisis de cobertura del servicio de la deuda (en miles de dólares) Cuentas 2017 2018

\begin{tabular}{lcc}
\hline $\begin{array}{l}\text { EBITDA (Utilidad Operativa + } \\
\text { Depreciaciones) } \\
\text { (/) Gastos Financieros + Deudas a C/P }\end{array}$ & $3 ` 418.047,09$ & $4 ` 194.930,36$ \\
\hline \multicolumn{1}{c}{ Total } & $8 ` 050.518,37$ & $9 ` 104.671,38$ \\
\hline
\end{tabular}

Elaborado por: Los autores

Fuente: Estados Financieros de Colineal Corporation Cía. Ltda., tomado de (Superintendencia de Compañías, valores y seguros , 2018)

\section{Flujo de caja libre}

El flujo de caja libre de la empresa Colineal tanto en el año 2017 como en el año 2018 son negativos; lo que significa es que la empresa no tiene el flujo de caja suficiente para cubrir sus necesidades operativas, si la empresa quisiera invertir en nuevos activos fijos tampoco lo podría realizar con el flujo normal de su operación, así mismo, sus necesidades operativas de financiamiento son altas, lo que demuestra que la empresa depende demasiado de los acreedores para poder cubrir las necesidades de efectivo.

\section{Tabla 29}

Análisis del flujo de caja libre (en miles de dólares)

\begin{tabular}{lll}
\hline Cuentas & $\mathbf{2 0 1 7}$ & $\mathbf{2 0 1 8}$ \\
\hline Utilidad Neta & $655.516,20$ & 1 `426.525,01 \\
(+) Depreciaciones & $191.679,77$ & $215.159,46$ \\
(-)Inversión en Activos Fijos (Estimado) & $1 ` 283.092,068$ & $1 ` 253.331,357$ \\
(-) Inversión en NOF (Estimado) & $755.674,5745$ & $717.637,0575$ \\
\hline Total & $\mathbf{- 2} \mathbf{4 7 4 . 6 6 2 , 7 4}$ & $\mathbf{- 1} \mathbf{5 8 2 . 6 1 5 , 3 0}$ \\
\hline
\end{tabular}

Elaborado por: Los autores

Fuente: Estados Financieros de Colineal Corporation Cía. Ltda., tomado de (Superintendencia de Compañías, valores y seguros , 2018)

\section{Valor Económico Añadido (EVA)}

Antes de calcular el EVA se debe determinar cada uno de los elementos que componen la fórmula. Primero, determinar el resultado neto después de impuestos, sumando los gastos financieros a la utilidad neta, porque estos no representan gastos de la operación normal de la empresa, a continuación, la tabla N. 29 muestra los valores correspondientes.

Tabla 30

Resultado neto después de impuestos

\begin{tabular}{|c|c|c|}
\hline Cuentas & 2017 & 2018 \\
\hline Utilidad Neta & $655.516,20$ & $1 ` 426.525,01$ \\
\hline (+) Gastos Financieros & $1 ` 414.484,61$ & $1 ` 594.151,59$ \\
\hline Resultado neto después de Impuestos & $2 \nmid 070.000,81$ & 3`020.676,60 \\
\hline
\end{tabular}

Elaborado por: Los autores

Fuente: Estados Financieros de Colineal Corporation Cía. Ltda., tomado de (Superintendencia de Compañías, valores y seguros , 2018) 
Tabla 31

Costo promedio de capital

\begin{tabular}{|c|c|c|c|c|c|}
\hline 2017 & & Valor & Distribución \% & Costo & Ponderación \\
\hline Préstamos & & 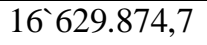 & 47.20 & 16.00 & 7.55 \\
\hline Bancarios & 0 & & & & \\
\hline Patrimonio Total & 4 & $18 ` 602.410,5$ & 52.80 & 11.13 & 5.88 \\
\hline Total & 4 & $35232.285,2$ & 100.00 & 25.13 & 13.43 \\
\hline 2018 & & Valor & Distribución \% & Costo & Ponderación \\
\hline $\begin{array}{l}\text { Préstamos } \\
\text { Bancarios }\end{array}$ & 1 & $159975.034,7$ & 42.34 & 16.00 & 6.77 \\
\hline Patrimonio Total & 9 & $21^{`} 753.072,2$ & 57.66 & 13.89 & 8.01 \\
\hline Total & $\mathbf{0}$ & $37728.107,0$ & 100.00 & 27.89 & 14.78 \\
\hline
\end{tabular}

Elaborado por: Los autores

Fuente: Estados Financieros de Colineal Corporation Cía. Ltda., tomado de (Superintendencia de Compañías, valores y seguros , 2018)

El costo promedio de la tasa de interés del capital, se lo obtiene del interés de los préstamos bancarios, que se consideró un 16\% anual tanto para el 2017 como 2018, y del Rendimiento Operativo del Patrimonio (ROE), que el 2017 fue de $11.13 \%$ y en el 2018 de $13.89 \%$; a estos resultados los dividimos para la distribución, luego se pondera de la ponderación de la tasa de interés, que en el 2017 fue de $13.43 \%$ y en 2018 de $14.78 \%$.

Tabla 32

Análisis del capital de trabajo invertido.

\begin{tabular}{lll}
\hline Cuentas & $\mathbf{2 0 1 7}$ & $\mathbf{2 0 1 8}$ \\
\hline Préstamos Bancarios & 16629874.70 & 15975034.71 \\
Patrimonio Total & 18602410.54 & 21753072.29 \\
\hline Capital Invertido & $\mathbf{3 5 2 3 2 2 8 5 . 2 4}$ & $\mathbf{3 7 7 2 8 1 0 7 . 0 0}$ \\
\hline
\end{tabular}

Elaborado por: Los autores

Fuente: Estados Financieros de Colineal Corporation Cía. Ltda., tomado de (Superintendencia de Compañías, valores y seguros , 2018)

Para calcular el capital invertido se suman los préstamos bancarios a corto y largo plazo, más el total del patrimonio. Con estos valores ya se puede calcular el EVA.

Tabla 33

Análisis del EVA

\begin{tabular}{lll}
\hline Cuentas & $\mathbf{2 0 1 7}$ & $\mathbf{2 0 1 8}$ \\
\hline Resultado neto después de impuestos & 2070000.81 & 3020676.60 \\
(-) Costo promedio ponderado de Capital & 4731695.91 & 5576214.21 \\
\hline Total & $\mathbf{- 2 6 6 1 6 9 5 . 1 0}$ & $\mathbf{- 2 5 5 5 5 3 7 . 6 1}$ \\
\hline
\end{tabular}

Elaborado por: Los autores

Fuente: Estados Financieros de Colineal Corporation Cía. Ltda., tomado de (Superintendencia de Compañías, valores y seguros , 2018)

Como se muestra en la tabla N. 33 la empresa Colineal no está generando valor agregado por su actividad operacional financiada netamente por los socios, se observa que los costos financieros son superiores a los costos de capital, es decir, son los acreedores financieros los que están generando valor agregado a la empresa; aunque en el año 2018 el 
EVA tuvo una leve mejoría no alcanzó para llegar a los niveles positivos que es lo ideal, se debe aumentar la participación de financiamiento por parte de los accionistas, para generar valor agregado con recursos propios.

\section{Conclusiones}

Una vez analizados los diferentes índices financieros, este estudio muestra como resultado que la empresa tiene un margen de utilidad aceptable frente al cumplimiento de las obligaciones, pese que no existe flujo de caja disponible para los accionistas. Sin embargo, la rotación de inventario es accesible y el uso óptimo de recursos ha permitido cumplir con los objetivos de la empresa, ya que las ventas crecen en un ritmo del $51.86 \%$.

Desde el punto de vista de la cobertura de intereses se analiza el EBITDA, el mismo que mide la utilidad operacional frente al interés. En el año 2017 y 2018 el EBITDA es menor frente a la cobertura de intereses, mostrando una utilidad muy baja si se consideraría que las tasas de interés por financiamiento están por alrededor del 14\%. Por tal motivo, se debería buscar generar utilidad por sobre esa tasa de interés, asumiendo los pagos, mediante la generación de valor que se puede aprovechar con las propiedades de inversión. Pese a esta realidad financiera, la empresa muestra solvencia frente a la economía empresarial por la gran oportunidad de cubrir con sus obligaciones, es decir, el costo de la deuda no afecta la rentabilidad productiva- empresarial. Así mismo, al tener la empresa un valor mayor en la utilidad operacional frente al EBITDA, esta muestra disponibilidad de caja, soportando los compromisos de deudas adquiridas. Los análisis anteriores del flujo de caja muestran que los valores que se han destinado en las inversiones, la empresa puede atender los pagos con los proveedores e instituciones financieras, tales como los diferentes bancos que revelan las notas explicativas a partir del año 2017.

Estas inversiones permiten la medición y sacar provecho de su riesgo financiero, gracias a la eficiencia que tiene la empresa en el capital neto de operación (KTN) y las compras de inventario. Puesto que al existir un aumento en el EBITDA se aumenta el flujo de caja libre, el mismo que permite el alto nivel de endeudamiento que asume la firma.

Al existir aumento en el capital de trabajo neto operativo representa que este debe ser financiado por el flujo de caja de la firma.

Para concluir con este apartado, la solvencia que tiene la empresa frente a su financiación es poco aceptable, pese a ello las alianzas estrategias que implementan pone en riesgo la sostenibilidad de la empresa en el mercado. Cabe recalcar que el retorno de capital de los inversionistas deberá ser valorada, debido a que su patrimonio está muy comprometido con los acreedores financieros, afectando la credibilidad de esta actividad y retrasando la posibilidad de generar ventajas competitivas.

\section{Bibliografía}

Acuña, G. A. (2016). Análisis y Planeación Financier. Colombia: Universidad Nacional de Colombia.

Angulo, D. y. (2012). La contabilidad financiera como base para la toma de decisiones en el marco organizacional. Revista Saber, Ciencia y Libertad. 
Azofra, P. V. (2017). Sobre el análisis financiero y su nueva orientación. Dialnet. Obtenido de file://D:/Users/Toshiba/Downloads/Dialnet-

SobreElAnalisisFinacieroYSuNuevaOrientacion-789667.pdf

Baena. (2014). Análisis Financiero: Enfoque y proyecciones. (Ecoediciones, Ed.)

Banco Central del Ecuador. (2019). Crecimiento económico-sector manufacturero. www.bce.edu.ec.

Boudreaux, K. (2016). Finanzas. En Finanzas (pág. 10). Estados Unidos: Edinburgh Business Scholl. Obtenido de Edinburgh Business School. Obtenido de https://www.ebsglobal.net/documents/course-tasters/spanish/pdf/fi-bk-taster.pdf

Camara de Industrias; Boletin de Política Económica; Centro de Investigaciones Económicas; Espol. (01 de 09 de 2018). Compañías-Sector-Manufacturero-Ecuatoriano-ESPE. Obtenido de http://www.cip.org.ec/wp-content/uploads/2018/09/Ranking-deCompanias-Sector-Manufacturero-Ecuatoriano-espa\%C3\%B1ol.pdf:

http://www.cip.org.ec/wp-content/uploads/2018/09/Ranking-de-Companias-SectorManufacturero-Ecuatoriano-espa\%C3\%B1ol.pdf

Cardona Olaya, J. L., Martínez, A., Velásquez, S. M., \& López , Y. M. (2014). Análisis de indicadores $\square$ nancieros del sector manufacturero del cuero y marroquinería: un estudio sobre las empresas colombianas. Colombia. Obtenido de file:///D:/Users/Toshiba/Downloads/Analisis_de_indicadores_financieros_del_sector_ man.pdf

Cheol, S. E., \& Bruce G., R. (2007). Administración Financiera Internacional (Cuarta ed.). México: Mc Graw Hill.

Colineal Corporation Cia Ltda. (2017). Obtenido de : http://www.colineal.com/acercade.html Crespo, M. (2018). Enfoque Gerencial en las empresas camaroneras . revista 100cs vol.4 Nol. EKOS. (2018). La Industria manufacturera: el sector de mayor aporte al PIB. EKOS. Obtenido de https://www.ekosnegocios.com/articulo/industria-manufacturera-el-sector-demayor-aporte-al-pib

El Universo. (Diciembre de 2018). Madera vendida en Ecuador tiene un origen ilegal. Ecología. Obtenido de https://www.eluniverso.com/noticias/2018/12/02/nota/7076118/40-madera-vendidatiene-origen-ilegal-ecuador

Eslava, J. d. (2010). La clave del análisis económico-financiero de la empresa (Segunda ed.). Pozuelo de Alarcón-Madrid: ESIC Editorial.

ESPAE. (2017). Fortaleciendo y desarrollando las capacidades de nuestros proveedores en la cadena de valor.

INEC. (2018). Instituto Nacional de Estadísticas y Censo . Obtenido de www.inec.gob.ec

Kiyosaki, R. (2015). El cuadrante del fujo del dinero . Bogotá- Colombia.

León, G. O. (2010). Administración Financiera. Fundamentos y aplicación (Cuarta ed., Vol. 4).

Maldonado, F., \& Proaño, G. (2015). BUSINNES EKO- LAS INDUSTRIAS EN ECUADOR. Quito-Ecuador: Ekos.

Martínez, A. E. (2005). Finanzas para directivos. México: McGraw-Hill Interamericana de España S.L.

Plan Nacional de Inversiones. (2019). Sector Forestal Produtivo del Ecuador. Obtenido de https://ecuadorforestal.org/informacion-s-f-e/sector-forestal-productivo-formal/

Puga, M. (2015). Definición de Finanzas. Obtenido de http://www.mpuga.com/docencia/Finanzas\%20I/Fundamentos\%20de\%20Finanzas\%2 0Texto.pdf

Ross, W., Randolf, \& Jordán, B. (2010). Fundamento de Finanzas Corporativas (Novena ed.). México: Mc Graw Hill. 
Superintendencia de Compañías, valores y seguros . (2018). Investigación y estudios sectoriales. Obtenido de Panorama de la Industria Manufaacturera en el Ecuador 20132017:

https://investigacionyestudios.supercias.gob.ec/wpcontent/uploads/2018/09/Panorama-de-la-Industria-Manufacturera-en-el-Ecuador2013-2017.pdf

Superintendencia de compañías, valores y seguros. (2018). Indicadores financieros del sector manufacturero. Obtenido de Industrias manufactureras: https://reporteria.supercias.gob.ec/portal/cgibin/cognos.cgi?b_action=cognosViewer\&ui.action=run\&ui.object $=\% 2 \mathrm{fcontent} \% 2 \mathrm{ffol}$ der\%5b $\% 40$ name $\% 3 \mathrm{~d} \% 27$ Reportes $\% 27 \% 5 \mathrm{~d} \% 2$ ffolder $\% 5 \mathrm{~b} \% 40$ name $\% 3 \mathrm{~d} \% 27$ Indicad ores $\% 27 \% 5 \mathrm{~d} \% 2$ freport $\% 5 \mathrm{~b} \% 40$ name $\% 3 \mathrm{~d} \% 27$ Indicadores $\% 20$ Sector $\% 20$ Empresa $\%$ 